IFN Working Paper No. 834, 2010

Planned Treatment and Outcomes in Residential Youth Care: Evidence from Sweden

\author{
Erik Lindqvist
}




\title{
Planned Treatment and Outcomes in Residential Youth Care: Evidence from Sweden
}

\author{
Erik Lindqvist* \\ Department of Economics, Stockholm School of Economics, Box 6501, SE-113 83 Stockholm, Sweden. \\ Research Institute of Industrial Economics (IFN), Box 55665, SE-102 15 Stockholm, Sweden
}

\begin{abstract}
A recurring theme in evaluations of Swedish residential youth care is that treatment is often unplanned. Using a data set of teenagers placed in youth care in $1991(N=357)$, we show that planned treatment - in the sense of a known expected duration of treatment - is strongly positively associated with treatment outcomes. In the short term, teenagers with planned treatment are 32 percent less likely to experience a treatment breakdown and 25 percent less likely to be reassigned to other forms of residential care after completed treatment. In the long term, teenagers with planned treatment are 21 percent less likely to engage in criminal behavior and 40 percent less likely to be hospitalized for mental health problems. The results are robust to controlling for a rich set of potentially confounding factors: Even though observable pre-treatment teenager characteristics explain about one fifth of the variation in criminal behavior 5-10 years after treatment, they have almost no predictive power for whether treatment is planned or unplanned.
\end{abstract}

Keywords: Residential youth care, juvenile delinquency, recidivism, principal-agent problems, bureaucracy.

\footnotetext{
*Tel.: +46-731504011; fax: +46-313207. E-mail address: erik.lindqvist@hhs.se.
} 


\section{Introduction}

Most western countries use some form of residential care for teenagers with severe behavioral problems. In Sweden, about 3,500 adolescents resided in a youth care facility as of November $1^{\text {st }} 2008$ (National Board of Health and Welfare, 2009). ${ }^{1}$ The majority of these teenagers are placed in care due to drug abuse or juvenile delinquency. Since every young adult who pursues a criminal career imposes a large cost on society, the success or failure of residential care has substantial effects on the welfare of society. Although some literature surveys indicate mixed or moderately positive effects of residential care (e.g., Garrett, 1985; Bates, English, \& Kouidou-Giles, 1997), there is arguably scope for improvement. For example, whereas 57 percent of the boys placed in Swedish residential care in 1991 had shown signs of criminal behavior when first placed in care, 73 percent were convicted for some crime as young adults. ${ }^{2}$ Even though these figures may not reflect a causal effect of treatment, they suggest that Swedish residential care does not succeed in keeping many teenagers from engaging in criminal behavior as adults. Moreover, teenagers placed in residential care fare badly in terms of mortality in early adulthood, earnings and educational attainment (Vinnerljung \& Sallnäs, 2008).

What explains the success or failure of residential care? Previous research has focused on how parental involvement (Jenson \& Whitaker, 1987), length of stay (Loughran et al., 2009), educational attainment (e.g., Trout et al., 2008), placement stability (e.g., Ward, 2009; Christiansen, Havik, \& Anderssen, 2010), teenager engagement (e.g., Englebrecht et al., 2008; Smith et al., 2008), physical restraint (Steckley, 2010), facility ownership (Bayer \& Pozen, 2005; Lindqvist, 2008), the punitiveness of the juvenile justice system (e.g. Levitt, 1998; Hjalmarsson, 2009) or peer-group effects among incarcerated teenagers (e.g. Bayer, Hjalmarsson, \& Pozen, 2009) affect outcomes. In this paper, we focus on the behavior of the bureaucracy - the social services - responsible for placing teenagers in care and monitoring its progression. A recurring theme in evaluations of Swedish residential care is that the social services do not provide adequate effort in terms of the planning and monitoring of care. As a result, many teenagers are placed in residential care without a plan for treatment.

We test whether the fact that treatment is planned is associated with better outcomes using a data set of teenagers placed in youth care in 1991. The data set is compiled by Vinnerljung, Sallnäs and Kyhle Westermark (2001) and contains detailed information on the teenagers' problems at the time of placement, treatment histories and socioeconomic outcomes in adult age. ${ }^{3}$ The data set also contains a variable for whether the expected duration of treatment was stated in advance. We argue that this constitutes a minimum requirement for treatment to be considered "planned". Previous research on residential youth care has suggested that teenagers in youth care benefit directly from knowing the expected duration of treatment (Levin, 1998, p. 153; Sallnäs, 2000, p. 186). Moreover, a plan for the length of stay is likely to presuppose an idea of the objective and content of treatment.

We first show that unplanned duration of treatment is associated with other symptoms of bad planning on the social services part. Social services that do not plan the duration of treatment are less likely to seek the consent of the teenager before placement, more likely to initiate treatment

\footnotetext{
1 "Adolescent" is defined here as between 13 and 21 years of age. The figure does not include teenagers in foster homes which is the most common form of out-of-home care in Sweden, nor does it include teenagers in state correctional facilities.

${ }^{2}$ These figures are computed from the data provided by Vinnerljung, Sallnäs and Kyhle Westermark (2001) and refer to teenagers in HVB-homes (see Section 2). Teenagers in state correctional facilities or foster homes are not included.

${ }^{3}$ Sallnäs, Vinnerljung and Kyhle Westermark (2004), Vinnerljung and Sallnäs (2008) and Lindqvist (2008) also use this data set.
} 
breakdowns and more likely to replace the teenager to another facility after the end of treatment. There are also systematic differences in terms of chosen treatment programs: Teenagers with planned treatment are placed in facilities which are more expensive, more likely to have a school within the facility and an explicit treatment program. Finally, planned treatment is associated with better long-run outcomes. As adults, teenagers with planned treatment are less likely to be convicted for a criminal offense or treated for mental health problems. Splitting the sample by sex reveals that the association between planned treatment and outcomes in our data is substantially stronger for boys. Though planned treatment is associated with better outcomes also for girls, the effect is generally not statistically significant.

The possibility that the empirical pattern discussed above is caused by non-random selection of teenagers cannot be ruled out. For example, it is conceivable that it is easier to plan treatment for teenagers with less severe problems. However, the statistical association between planned treatment and outcomes is robust to controlling for a rich set of teenager pre-treatment characteristics. Though the set of observable teenager pre-treatment characteristics explains about one fifth of the variation in adult outcomes, it has no predictive power for whether a placement is planned or not.

\section{Residential Youth Care in Sweden}

Residential care is the most comprehensive measure for youth at risk which the Swedish social services can undertake. Most teenagers are placed in residential care due to their own behavior, such as violent crime, drug addiction, or suicidal tendencies. There are two different types of residential youth care facilities in Sweden. First there are state correctional facilities (Särskilda ungdomshem or \$12-homes in Swedish), which treat teenagers with the most serious problems. This study focuses on the other type of facility, HVB-homes, which are both run by private and public principals.

The responsibility to act when children have some kind of social problem lies at the municipality level, the lowest tier in Swedish government. It is the municipality social service that acts as buyer in the market for residential youth care. Though each placement must be confirmed by a political committee, the decision to place a teenager in youth care is prepared and implemented by a social welfare secretary (caseworker), employed by the municipality. At the seller side, public facilities are managed by municipalities or county councils, whereas private facilities are run by firms or non-profit organizations. ${ }^{4}$

A recurring theme in evaluations of Swedish residential care is that the social services do not provide adequate effort in terms of the planning and monitoring of care. According to Sallnäs (2005), 60 percent of 97 interviewed managers at private facilities said that the social services "rarely" or "never" asked for evaluations of treatment quality when placing a teenager at their facility. The Swedish National Audit Office (2002) argued that the municipalities' lack of adequate monitoring is a major problem of Swedish residential youth care. According to Levin (1998, p.140), only 16 percent of 61 former residents at Råby (a correctional center) rated the contact with the social welfare secretary responsible for their case as "good", while 54 percent rated their contact as "bad" or "no contact". Many teenagers also experience a high turnover of social welfare secretaries (Levin 1998, p.142). In an extensive survey of the research on youth care in Sweden and other countries, Andreassen (2003) concluded that a large fraction of residential youth care is not undertaken according to the established principles of effective treatment.

\footnotetext{
${ }^{4}$ The counties constitute the second tier in Swedish government, in between the State and the municipalities.
} 
Since 2001, Swedish law states that the municipality social services must make a plan for treatment before placing a child or teenager in care. ${ }^{5}$ Among other things, this plan should state the objective and duration of treatment (County Council of Västra Götaland, 2004). ${ }^{6}$ Compliance is low, however, as indicated by evaluations undertaken by a number of County Councils. ${ }^{7}$ A recurring theme in these evaluations is that treatment plans are often short and expressed in general terms with little reference to the treatment needs of the teenager in question. Even the most basic aspects of treatment, like treatment objectives and expected duration, are often missing. For example, consider the following quote from the County Council of Gotland (2005, p. 2): "It is the opinion of the County Council that several of the examined treatment plans are so short and formulated in such general terms that they cannot be called individual treatment plans" (translation from the original Swedish by the author). After evaluating 89 placements of teenagers from 16 different municipalities, the County Council of Västra Götaland concluded that treatment plans vary a lot in terms of quality and that there was no reference to the expected duration of treatment in $39.3 \%$ of cases. The County Council of Kronoberg (2006) found that 5 out of 21 evaluated placements had no treatment plan at all, and that a large proportion of the treatment plans that did exist were not intelligible. The harsh criticism of the County Councils is remarkable given that the evaluations refer to the period after the law was changed in 2001 to make individual treatment plans a prerequisite for all placements in youth care.

We argue that the lack of effort on the social services part reflects an agency problem. Several factors limit the accountability of the social services. Quality is inherently difficult to measure in residential youth care and information regarding the decisions to place a teenager in care is not publicly available. As employees of the municipality administration, social welfare secretaries have extensive employment protection. Teenagers with social problems (and their families) do not constitute a strong group in society. Although the municipality social services' lack of adequate planning and monitoring has repeatedly been subject to harsh criticism from various other government bodies, there are no sanctions attached to this critique.

\section{Data}

Our data set was originally compiled by Vinnerljung, Sallnäs and Kyhle Westermark (2001) and is based on the files of all Swedish adolescents (13-16 years of age) who were placed in a HVB-home during 1991, with the exception of teenagers who were only placed in a HVB-home temporarily or for the sole purpose of having their treatment needs assessed before assigned to their final placement. ${ }^{8}$ There are some missing observations where the files could not be found or were impossible to interpret. ${ }^{9}$ We also exclude one facility from the sample where treatment took the form of long, large-

\footnotetext{
${ }^{5}$ SoL, 11 kap $3 \S$.

${ }^{6}$ The concept of "planned treatment" which we consider in this paper is not identical to the existence of a "treatment plan" as defined in the evaluations of the County Councils (though, of course, they are strongly related). For example, treatment plans should contain certain aspect of treatment that we do not include into the concept of "planned treatment", such as a description of how teenagers can maintain contacts with their family while in care. Moreover, as will be made clear below, actual treatment plans may not be detailed enough to warrant the label of "planned treatment" (not least because many treatment plans lack information about the expected duration of treatment).

${ }^{7}$ The County Councils have the formal responsibility to monitor the municipality social services. I have considered evaluations from the County Councils of Gotland, Västra Götaland and Kronoberg.

${ }^{8}$ The data collection process is described in detail in Vinnerljung, Sallnäs and Kyhle Westermark (2001) and Sallnäs, Vinnerljung and Kyhle Westermark (2004).

${ }^{9}$ This was the case for about one in three placements from Stockholm and Malmö, Sweden's largest and third largest city, but only for about one in thirty placements from the rest of the country. According to Vinnerljung, Sallnäs and Kyhle Westermark (2001), there is nothing that indicates that the missing files were concentrated on a certain group of children. Yet if Stockholm and Malmö differ systematically from the rest of the country in terms of the teenagers they place in residential care, the sample will not be fully representative.
} 
scale sailing trips. The teenagers were followed as long as they were subject to residential care, or until their 18th birthday. In addition, the data set contains information on post-treatment outcomes at the age of 25. The data on post-treatment outcomes come from various sources of register data collected by different government agencies. See Vinnerljung and Sallnäs (2008) for a detailed account of these data. In total, the data set consists of 357 placements of 336 different teenagers in 173 facilities. ${ }^{10}$ The number of observations from a single facility varies from 1 to 10 .

The teenagers differ in terms of treatment history and the reason for placement. Sixty-one percent of the teenagers in the data were placed in youth care due to their own behavior. The second and third most common motives for placement were relational problems (39 percent) and lack of care and attention $\left(27\right.$ percent). ${ }^{11}$ There is a large variation in the teenagers' problems: 22 percent had psychological problems, 34 percent were addicted to drugs, 40 percent had committed crimes and 19 percent were considered violent. Many teenagers had multiple problems.

In addition to teenager pre- and post-treatment characteristics, the data set contains information on basic facility characteristics (type of ownership, treatment places, personnel density and type of offered treatment programs) as well as basic demographic characteristics of the municipality placing the teenager in care. ${ }^{12}$

The data set also contains an indicator variable for whether the expected duration of treatment was stated in advance of treatment. ${ }^{13}$ The majority of placements in our data (70 percent) did not have a time plan at the onset of treatment. There are two reasons to expect that the existence of a time plan is associated with better outcomes. First, not knowing the expected duration of treatment could have a direct effect on the probability of successful treatment. Based on his interviews with former residents at Råby correctional center, Levin (1998, p. 154) argued that indeterminate length of treatment has a discouraging effect on the teenagers motivation for treatment, and increases the risk of escape and unruly behavior at the facility. Relatedly, many former residents stated that the objective of treatment was never made clear to them. Second, there are reasons to presume that the social services that do not plan the duration of treatment in advance are also more prone to miss out on other aspects of planning before the onset of treatment. The existence of a plan for the duration of treatment arguably requires an idea of both the content and objective of treatment. Moreover, the existence of a time plan is likely to reflect a general preference on the social services part for planning treatment in advance.

\footnotetext{
${ }^{10}$ As my interest is in the effect of treatment plans on outcomes, I use placements as my unit of analysis. This raises two different issues. First, as some teenagers experienced more than one placement, the sample is not perfectly representative with respect to the set teenagers that were ever placed in youth care. Second, placements for the same teenager might not be independent observations. In order to check the first problem, I have run the main regressions reported below excluding all placements in HVB-care expect the first for every teenager. To deal with the second problem, I run the same regressions with standard errors clustered at the teenager level. The results do not change substantially in any of these cases and are available upon request.

${ }^{11}$ There can be more than one motive for placing a teenager in youth care.

${ }^{12}$ Some of the information regarding facility ownership and municipality characteristics has been added to the original data set in Vinnerljung, Sallnäs and Kyhle Westermark (2001) by the author or this paper.

${ }^{13}$ Note that expected duration of treatment need not equal the actual duration. For example, treatment could break down before the expected end, or the facility and the social services could agree that treatment should be prolonged beyond plan. However, the expected and planned durations are equal for the median placement and 73 percent of placements without a treatment breakdown deviate from the planned duration by less than 6 months. Naturally, it is not possible to come up with any corresponding figures for placements with no stated expected duration. Lindqvist (2008) argues that private facilities tend to prolong treatment periods in order to increase reimbursement from the social services. However, there is no evidence in the data that placements with an expected duration of treatment are more or less likely to be sent to private facilities (see Table 1).
} 
Henceforth, we will refer to placements with a plan for the duration of treatment as "planned" and those without a plan as "unplanned". Admittedly, to have a plan for how long a treatment period should last is only a small part of what should be required for treatment to be considered "planned". However, we argue that the existence of a plan for the expected duration of treatment constitutes a minimum requirement for treatment to be considered "planned".

We now turn to a discussion of the different outcome measures considered in the empirical analysis. The social services can place teenagers in care under two different laws. The first law (Socialtjänstlagen) requires the consent of the teenager placed in care or, in case the teenager is below 15 years of age, the consent of his or her parents. The other law (Lagen om Vård av Unga) enables the social services to force teenagers into care. Which law is adopted is likely to depend on both teenager characteristics and the effort put down by the social services to motivate teenagers and their parents for treatment. We first consider voluntary placement as a dependent outcome variable, but control for it in the subsequent analysis with other dependent variables. The motivation for this analysis is to see whether social services that do not plan treatment in advance also differ in other aspects of the preparation for treatment.

We consider three different treatment outcomes: reassignment to another facility after completed treatment, treatment breakdown and the duration of treatment. There are strong reasons to presume that reassignments and breakdowns are indicators (and perhaps also causes) of unsuccessful treatment. The definition of breakdown is that "a placement is ended abruptly and without planning" (Vinnerljung, Sallnäs, \& Kyhle Westermark et al. 2001, p. 67, translated by the author). ${ }^{14}$ Placements that end because treatment objectives have been reached are not considered treatment breakdowns. While reassignments and treatment breakdowns indicate unsuccessful treatment, it is not obvious whether the duration of treatment is an indication of successful or unsuccessful treatment. However, it is instructive to see whether a plan for the duration of treatment is systematically associated with the actual duration of treatment.

The data also allows us to test whether planned treatment is associated with better outcomes in adult age. Whereas treatment outcomes pertain to a particular placement, outcomes in adult age refer to a particular individual, with a history of treatment which may go beyond a single placement. For example, some teenagers were replaced to another facility during 1991. In addition, teenagers have different treatment histories prior to 1991 and some continue treatment after the last placement we observe in the data. When a teenager experienced more than one placement in 1991, we consider the placement with the longest duration. We exclude four teenagers from the sample where the difference between the longest and second longest placement was one month or less.

Table 1 gives summary statistics for all right-hand side variables used in the empirical analysis depending on whether or not treatment was planned. As shown in Table 1, teenagers with planned and unplanned treatment had similar pre-treatment characteristics. The only difference which is close to being statistically significant is that teenagers with unplanned treatment are more likely to have engaged in criminal behavior. By contrast, there are some significant differences in terms of the facilities chosen by the social services. Social welfare secretaries who plan the duration of treatment are more likely to send teenagers to large facilities and to facilities run by private non-profit organizations. There are also some noteworthy differences with respect to the content of care. Teenagers with planned treatment are more likely to be placed in facilities with a school at the facility and facilities that practice "milieu therapy", but significantly less likely to be placed in facilities that

\footnotetext{
${ }^{14}$ See also Sallnäs, Vinnerljung and Kyhle Westermark (2004) for a discussion of the concept of "treatment breakdown" as defined in this data.
} 
focus on creating a "family-like atmosphere". These results indicate that teenagers with planned treatment are sent to facilities that are characterized by a higher level of professionalism. It is, however, not clear whether such professionalism actually benefits teenagers.

\section{[TABLE 1 ABOUT HERE]}

There are also some observable differences across geographical areas. Municipalities within greater Stockholm and Svealand (the middle region of Sweden) are more prone to plan the duration of treatment, whereas municipalities in Götaland (the southern region) are less likely to do so. There are also strong indications in the data that whether treatment is planned or not is decided at the municipality level, or by individual social welfare secretaries, rather than by facilities or specific teenager characteristics. Regressing a dummy variable for planned duration of treatment on the full set of facility characteristics gives an adjusted $R^{2}$ of 0.006 . The adjusted $R^{2}$ is -0.01 when the dummy for planned treatment is regressed on the full set of teenager characteristics. In comparison, the set of municipality dummies has more explanatory power with an adjusted $R^{2}$ of 0.12 .

The low explanatory power of the relatively extensive set of teenager characteristics suggests that non-random selection of teenagers to planned treatment is not a major problem in this context. Still, a potential concern is that social services that do not plan the duration of treatment are less prone to make notes about the teenagers' problems, thereby creating a reporting bias. In order words, teenagers with unplanned treatment could appear to have less severe problems than they actually do. However, since teenagers with planned treatment do not differ in terms of their observable characteristics, a reporting bias is not consistent with random assignment of teenagers to facilities. Moreover, in case of a reporting bias, we would expect systematic differences in the documentation of teenager characteristics that depend upon the judgment of the social services (e.g. whether a teenager had problems at home during childhood) and obvious facts that do not involve subjective judgment (sex, age, previous experience of youth care). The fact that all teenager characteristics (except criminal behavior) are similar for teenagers with and without a planned duration of treatment thus supports the view that reporting bias is not a major problem in the data.

A related concern is that the social services may manipulate the files of teenagers ex post. This could give rise to an endogeneity problem as planned treatment may be a function of treatment outcomes. Yet there are two reasons why this is unlikely to be an important problem. First, as explained above, there are no sanctions against municipalities that do not plan treatment. Second, the incentive to manipulate files ex post would arguably be stronger in case of bad outcomes, creating a bias against finding an association between planned treatment and good outcomes. Note that ex post changes in the teenager files with respect to planned treatment that are independent of treatment outcomes will bias the estimated relationship between planned treatment and outcomes toward zero.

\section{Estimation}

Consider the regression equation

$$
y_{i j k}=\alpha+\beta_{1} \operatorname{plan}_{i j k}+X_{i} \beta_{X}+Y_{j} \beta_{Y}+Z_{k} \beta_{Z}+T_{k} \beta_{T}+\varepsilon_{i j k}
$$

where $y_{i j k}$ is some outcome measure for teenager $i$ from municipality $j$ placed in facility $k$ and plan $_{i j k}$ is a dummy variable that takes the value one if the duration of treatment was planned in advance. $X_{i}$ is a vector of teenager characteristics; $Y_{j}$ is a vector of municipality characteristics; $Z_{k}$ 
is a vector of basic facility characteristics and $T_{k}$ is a vector of treatment characteristics. The exact variables in each vector are given by Table 1 . Standard errors are clustered at the facility level in all regressions, except in the specification with facility fixed effects.

Our interest lies in the partial correlation between planned treatment and different outcomes, i.e., $\beta_{1}$. The interpretation of $\beta_{1}$ depends on which sets of control variables are included in the regression. We consider seven different specifications of regression (1). The first specification has no covariates and just gives the difference in the proportion of teenagers with certain outcomes depending on plan $_{i j k}$

. Since the main econometric concern in this context is that teenagers with planned treatment are systematically different from those with unplanned treatment, we include the vector of teenager covariates, $X_{i}$, in specification 2 . If observable teenager characteristics constitute a random subset of all teenager characteristics, the change in the estimated size of $\beta_{1}$ when teenager characteristics are added in specification 2 is informative about the bias that remains due to lack of a complete set of covariates (Altonji, Elder and Taber, 2005). If the estimated size of $\beta_{1}$ does not change much from controlling for observable teenager characteristics, then this suggest that the remaining bias is small. It is important in this context that the set of teenager characteristics are informative about the true extent of the teenagers' problems. Regressing dummy variables for convictions and imprisonment in adult age on the set of teenager characteristics gives an adjusted $R^{2}$ of 0.17 and 0.22 and the null hypothesis of joint insignificance is strongly rejected in both cases. Consequently, even though observable teenager characteristics do not predict whether a placement is planned or unplanned (as shown above), observable teenager characteristics do have substantial predictive power for criminal behavior 5-10 years after the onset of treatment. Note that since teenagers are subject to many random influences between the time of placement and young adulthood (e.g., youth care itself), we would not be able to explain all variation in adult outcomes even if we had access to the universe of covariates at the time of placement.

Another potential selection problem is that social services that are prone to plan the duration of treatment differ systematically in other respects. We therefore include municipality characteristics along with teenager characteristics in specification 3.

The remaining four specifications test for various forms of mechanisms by which treatment plans may correlate with outcomes. If the main channel is the choice of facility, then the effect of treatment plans should be reduced as we include controls for facility characteristics $(4,5,6)$, treatment characteristics $(5,6)$ or facility fixed effects (7). If planned treatment is, in itself, important for outcomes in residential youth care, then the estimated effect should be the same across the full set of specifications (1-7). Our favored specification for estimating the total effect of planned treatment on outcomes is specification 3 with teenagers and municipality characteristics, but no controls for facility characteristics.

\section{Results}

The results from regression (1) are reported in Table 2. The first row shows the partial correlation between planned treatment and voluntary placement for different sets of control variables. Column 1 in the first row shows that teenagers with planned treatment are more likely to be placed in care voluntarily. Column 2 reveals that this correlation is robust to controlling for teenager characteristics, suggesting that the relationship between planned treatment and voluntary placement is caused by the behavior of the social services rather than by certain teenager characteristics. Controlling for municipality, facility or treatment characteristics in columns 3-7 does not change the partial 
correlation between planned treatment and non-voluntary placement appreciably, even though it is not statistically significant in the regression with facility-fixed effects. Consequently, we find no evidence that the higher proportion of non-voluntary placements among teenagers without a treatment plan is caused by other observable factors. However, as selection of unobservable characteristics cannot be completely ruled out, we include a dummy variable for voluntary placement in all subsequent regressions with controls for teenager characteristics.

As shown in the second row of Table 2, there is no association between planned treatment and the duration of treatment. However, the third row shows that unplanned placements are significantly more likely to end in a treatment breakdown, and that this effect is robust to controlling for teenager and municipality characteristics. The size of the effect is substantial: planned treatment reduces the risk of a treatment breakdown by 11 percentage points - or 32 percent. Controlling for facility characteristics in column 4 and onwards decreases the estimated effect by about 3 percentage points, suggesting that part of the higher breakdown frequency is explained by the social services' choice of facility. The fourth row shows that part of the higher breakdown frequency for unplanned placements is due to breakdowns initiated by the social services. Finally, the fifth row reveals that teenagers with planned treatment are less likely to be replaced into another facility after treatment ended.

Overall, the results in Table 2 suggest that planned treatment is positively associated with treatment outcomes. Social services that do not plan the duration of treatment in advance are more prone to use legal force in placing teenagers, to stop treatment on a short notice and to replace teenagers after treatment. In short, unplanned treatment is part of a pattern that indicates ill-prepared social services.

\section{[TABLE 2 ABOUT HERE]}

Table 3 shows that planned treatment is associated with better outcomes in adult age. Teenagers with treatment plans are less likely to have been convicted for any type of crime, or a violent crime, between the age of 20 and 24. In neither of these cases do we find that controlling for teenager, municipality or facility characteristics affect the partial correlation between planned treatment and outcomes. Planned treatment is also negatively associated with the probability of being imprisoned, but this effect is never statistically significant. We also find a strong, negative effect of planned treatment on mental health, but no effect on educational attainment and economic self-sufficiency. ${ }^{15}$

\section{[TABLE 3 ABOUT HERE]}

Table 4 shows the results when we run regression (1) for a subset of the treatment and posttreatment outcomes and split the sample according to sex. Notably, the association between planned treatment and outcomes is much stronger for boys. Though planned treatment is associated with better outcomes for girls, the coefficient estimate is never statistically significant. One interpretation of these results is that boys suffer more from the uncertainty induced by unplanned treatment. Interestingly, Egelund and Vitus (2008) find a similar pattern in their analysis of treatment breakdown of Danish teenage placements. In their data, the lack of a care plan was associated with a significantly higher risk of treatment breakdown for boys but not for girls. Care plans were, however, associated with higher stability of care for both boys and girls.

\footnotetext{
${ }^{15}$ The significance levels in Table 2 are not adjusted for the fact that we test several different hypotheses. Also note, however, that only specification 1, 2 and 3 are intended to estimate the effect of planned treatment on outcomes. Since the aim of specification 4-7 is to test how the point estimate change when adding variables that reflect potential mechanisms by which planned duration affect outcomes, the larger standard errors in these regressions do not imply that planned duration is not a statistically significant predictor of post-treatment outcomes.
} 


\section{[TABLE 4 ABOUT HERE]}

\section{Discussion}

Most previous research on residential care has focused on the direct aspects of treatment. This paper is instead is related to a small literature on how the caseworker process affects outcomes in residential care. Based on interviews with former residents at the state correctional facility Råby in Sweden, Levin (1998) argued that indeterminate length of stay and unclear objectives for treatment have a negative effect on treatment outcomes. Relatedly, Egelund and Vitus (2008) found that lack of a care plan is associated with lower placement stability in study of Danish teenagers. The results in this paper - that planned treatment is associated with better outcomes - thus confirm those of the previous literature.

Why is planned treatment associated with better outcomes in the short and long run? We identify three potential mechanisms. First, as argued by Levin (1998), knowing the expected duration of treatment in advance may, in itself, be important for motivating teenagers for treatment.

Second, our results indicate that unplanned treatment is just one of many symptoms of bad planning on the social services part. Social services that do not plan the duration of treatment in advance are less likely to seek the consent of parents and teenagers before placing them in a facility, more likely to initiate treatment breakdowns and to replace teenagers in another facility after the end of treatment.

Third, the fact that teenagers with planned treatment are placed in facilities that are more expensive, have nonprofit status, a school at the facility, more treatment places and other types of therapy suggest that social services that plan treatment select different facilities, though it is not obvious that these facility characteristics actually reflect higher quality. Controlling for observable facility and treatment characteristics has only a modest effect on the statistical association between planned treatment and outcomes, suggesting that choice of facility is not the main cause of the association between planned treatment and outcomes.

Regardless of which mechanism is most important, the paper points to the importance of providing caseworkers with incentives to plan and monitor placements in residential youth care. Although different government bodies have repeatedly criticized the municipality social services for failing in these respects, there are no sanctions attached to this criticism.

\subsection{Limitations}

There are four limitations of the present study. First, it is not clear exactly why a planned duration treatment is associated with better outcomes. There are reasons to presume that a time plan for treatment is correlated with other aspects of planning, but we cannot be certain that this is the case. An ideal data set would contain detailed information on both the preparations undertaken by the social services and the type of treatment undertaken at the residential facilities. Second, teenagers are not randomly assigned to different degrees of pre-treatment planning. Although our results are robust to controlling for a wide range of teenager characteristics, the possibility that the results are driven by selection on unobservable characteristics cannot be ruled out. A third limitation this study shares with many other studies on out-of-home care is that the relatively small sample size makes estimation imprecise. Finally, since the teenagers in the data were placed in care in 1991, one could ask whether the results in the paper are relevant today. Although there is no way to be sure about this, we believe that the answer is yes. As shown in Section 2 of this paper, the incompleteness of treatment plans has been a recurring theme is evaluations of Swedish residential care over the last decade. 


\section{Conclusion}

This paper has shown that planned treatment - in the sense of an expected duration of treatment - is associated with better treatment outcomes in residential youth care, in particular for boys. The results remain robust after controlling for observable pre-treatment characteristics, although selection problems cannot be ruled out completely. The results are in line with previous research and point to the importance of providing adequate incentives for caseworkers. However, more work is needed before we can pin down the exact mechanism by which the planning of treatment affects outcomes.

\section{Acknowledgement}

I am thankful to Bo Vinnerljung and Marie Sallnäs for generously providing me with their data and for many helpful comments. Aron Berg provided valuable research assistance. Financial support from the Jan Wallander and Tom Hedelius Foundation is gratefully acknowledged. I am responsible for any remaining errors.

\section{References}

Altonji, J., Elder, T., \& Taber, C. (2005). Selection on observable and unobservable variables: Assessing the effectiveness of Catholic schools. Journal of Political Economy, 113(1), 151-184.

Andreassen, T. (2003). Institutionsbehandling av ungdomar - Vad säger forskningen? Stockholm: Centrum för utvärdering av socialt arbete och Statens institutionsstyrelse.

Bates, B. C., English, D. J., \& Kouidou-Giles, S. (1997). Residential treatment and its alternatives: A review of the literature. Child and Youth Care Forum, 26(1), 1-45.

Bayer, P., \& Pozen, D. E. (2005). The effectiveness of juvenile correctional facilities: Public versus private management. Journal of Law and Economics, 48(2), 549-589.

Bayer, P., Hjalmarsson, R., \& Pozen, D. (2009). Building criminal capital behind bars: Peer effects in juvenile corrections. Quarterly Journal of Economics, 124(1), 105-147.

Christiansen, Ø., Havik, T., \& Anderssen, N. (2010). Arranging stability for children in long-term outof-home care. Children and Youth Services Review, 32(7), 913-921.

County Council of Gotland (2005). Vårdplaner. Länsstyrelsen i Gotlands Län.

County Council of Kronoberg (2006). Vårdplaner och behandlingsplaner. Meddelande 2006:2, Länsstyrelsen i Kronobergs Län.

County Council of Västra Götaland (2004). Vårdplan vid SoL-placering. Rapport 2004:10, Länsstyrelsen i Västra Götalands Län.

Egelund, T., \& Vitus, K. (2008). Breakdown of care: the case of Danish teenage placements. International Journal of Social Welfare, 18(1), 45-56.

Englebrecht, C., Peterson, D., Scherer, A., \& Naccarato, T. (2008). 'It's not my fault': Acceptance of responsibility as a component of engagement in juvenile residential treatment", Children and Youth Services Review, 30(4), 466-484.

Garrett, C. J. (1985). Effects of residential treatment on adjudicated delinquents: A meta-analysis. Journal of Research in Crime and Delinquency, 22(4), 287-308. 
Hjalmarsson, R. (2009). Juvenile jails: A path to the straight and narrow or to hardened criminality? Journal of Law and Economics, 52(4), 779-809.

Jenson, J. M., \& Whittaker, J. K. (1987). Parental involvement in children's residential treatment: From preplacement to aftercare. Children and Youth Services Review, 9(2), 81-100.

Levin, C. (1998). Uppfostringsanstalten: om tvång i föräldrars ställe, Lund: Arkiv förlag.

Levitt, S. D. (1998). Juvenile Crime and Punishment. Journal of Political Economy, 106(1), 11561185.

Lindqvist, E. (2008). Privatization of credence goods: Evidence from residential youth care. IFN Working Paper 794.

Loughran, T. A., Mulvey, E. P., Schubert, C. A., Fagan, J., Piquero, A. R. \& Losoya, S. H., (2009). Estimating a dose-response relationship between length of stay and future recidivism in serioys juvenile offenders. Criminology, 47(3), 699-40.

National Board of Health and Welfare (2009). Barn och unga - insatser 2008. Article number 2009125-20, Socialstyrelsen, Stockholm.

Sallnäs, M. (2000), Barnavårdens institutioner - framväxt, ideologi och struktur, Socialhögskolan, Stockholms universitet, Stockholm.

Sallnäs, M. (2005). Vårdmarknad med svårigheter - om privata aktörer inom institutionsvården för barn och ungdomar. Socialvetenskaplig tidskrift, 12(2-3), 226-245.

Sallnäs, M., Vinnerljung, B., \& Kyhle Westermark, P. (2004). Breakdown of teenage placements in Swedish foster and residential care. Child and Family Social Work, 9(2), 141-152.

Smith, B., Duffee, D. E., Steinke, C. M., Huang, Y., \& Larkin, H. (2008). Outcomes in residential treatment for youth: The role of early engagement. Children and Youth Services Review, 30(12), $1425-1436$.

Steckley, L. (2010). Containment and holding environments: Understanding and reducing physical restraint in residential child care. Children and Youth Services Review, 32(1), 120-128.

Swedish National Audit Office (2002). Tillsyn av behandlingshem för barn och ungdomar. Riksrevisionsverket rapport 2002:6, Riksrevisionsverket, Stockholm.

Trout, A. L., Hagaman, J., Casey, K., Reid, R., \& Epstein, M. H. (2008). The academic status of children and youth in out-of-home care: A review of the literature. Children and Youth Services Review, 30(9), 979-994.

Vinnerljung, B., \& Sallnäs, M. (2008). Into adulthood: a follow-up study of 718 young people who were placed in out-of-home care during their teens. Child and Family Social Work, 13(2), 144-155.

Vinnerljung, B., Sallnäs, M., \& Kyhle-Westermark, P. (2001). Sammanbrott vid tonårsplaceringar om ungdomar i fosterhem och på institution, CUS - Socialstyrelsen, Stockholm. 
Ward, H. (2009). Patterns of instability: Moves within the care system, their reasons, contexts and consequences. Children and Youth Services Review, 31(10), 1113-1118. 
Table 1. Summary statistics by treatment status

\begin{tabular}{|c|c|c|c|c|c|}
\hline & \multicolumn{2}{|c|}{ Planned duration } & \multicolumn{2}{|c|}{ Not planned duration } & \multirow[b]{2}{*}{$p$-value } \\
\hline & $N$ & Freq. & $N$ & Freq. & \\
\hline \multicolumn{6}{|l|}{ Teenager characteristics } \\
\hline Previous experience of residential care & 107 & 0.38 & 250 & 0.36 & 0.677 \\
\hline Previous breakdown & 102 & 0.31 & 242 & 0.30 & 0.765 \\
\hline Psychological problems & 107 & 0.20 & 250 & 0.23 & 0.456 \\
\hline Some addiction (alcohol, drugs \& snorting) & 107 & 0.35 & 250 & 0.34 & 0.858 \\
\hline Problems evaluated at state correctional facility & 106 & 0.09 & 249 & 0.08 & 0.570 \\
\hline Sex $($ Male $=1)$ & 107 & 0.47 & 250 & 0.54 & 0.208 \\
\hline Age in 1991 & 107 & 14.85 & 250 & 14.87 & 0.858 \\
\hline Immigrant & 107 & 0.36 & 250 & 0.38 & 0.837 \\
\hline Previous placement some form of treatment & 106 & 0.35 & 246 & 0.34 & 0.891 \\
\hline Placed in youth care due to own behavior & 107 & 0.64 & 250 & 0.60 & 0.484 \\
\hline Criminal behavior & 107 & 0.34 & 250 & 0.42 & 0.122 \\
\hline Violent behavior & 107 & 0.21 & 250 & 0.18 & 0.497 \\
\hline Problems at home during childhood & 107 & 0.59 & 250 & 0.56 & 0.615 \\
\hline \multicolumn{6}{|l|}{ Facility characteristics } \\
\hline Private facility & 107 & 0.49 & 250 & 0.48 & 0.863 \\
\hline County facility & 106 & 0.37 & 246 & 0.38 & 0.801 \\
\hline Nonprofit facility & 104 & 0.20 & 239 & 0.13 & 0.068 \\
\hline Distance exceeding $100 \mathrm{~km}$ & 107 & 0.26 & 250 & 0.27 & 0.902 \\
\hline Places at facility & 104 & 11.07 & 238 & 8.89 & 0.028 \\
\hline Personnel density & 102 & 1.24 & 237 & 1.20 & 0.488 \\
\hline Cost $(1,000 \text { SEK per month })^{*}$ & 100 & 50.99 & 221 & 46.77 & 0.042 \\
\hline \multicolumn{6}{|l|}{ Treatment characteristics } \\
\hline Assessment & 103 & 0.21 & 235 & 0.18 & 0.451 \\
\hline School at facility & 103 & 0.35 & 235 & 0.25 & 0.052 \\
\hline Work part of treatment & 103 & 0.05 & 235 & 0.04 & 0.663 \\
\hline Family-like atmosphere & 103 & 0.03 & 235 & 0.10 & 0.029 \\
\hline Milieu therapy & 103 & 0.39 & 235 & 0.21 & 0.001 \\
\hline Other & 103 & 0.16 & 235 & 0.20 & 0.332 \\
\hline Not stated & 104 & 0.01 & 245 & 0.04 & 0.127 \\
\hline Co-residency ("medlevarskap") & 103 & 0.13 & 235 & 0.10 & 0.514 \\
\hline \multicolumn{6}{|l|}{ Municipality characteristics } \\
\hline Log of population in 1990 & 99 & 11.47 & 226 & 11.34 & 0.418 \\
\hline Right-wing political majority & 98 & 0.37 & 220 & 0.37 & 0.927 \\
\hline Geography dummy: "Göteborg" & 99 & 0.10 & 226 & 0.11 & 0.888 \\
\hline Geography dummy: "Stockholm" & 99 & 0.35 & 226 & 0.20 & 0.003 \\
\hline Geography dummy: "Malmö" & 99 & 0.06 & 226 & 0.03 & 0.134 \\
\hline Geography dummy: "Götaland" & 99 & 0.35 & 226 & 0.51 & 0.008 \\
\hline Geography dummy: "Svealand" & 99 & 0.55 & 226 & 0.38 & 0.005 \\
\hline Geography dummy: "Norrland" & 99 & 0.10 & 226 & 0.11 & 0.797 \\
\hline
\end{tabular}

The variable Cost is not included in the set of control variables. The rightmost column gives the $p$-value of a test of equal proportions between planned and unplanned placements. 
Table 2. Treatment outcomes

\begin{tabular}{|c|c|c|c|c|c|c|c|}
\hline Dependent variable & (1) & (2) & (3) & (4) & (5) & (6) & (7) \\
\hline \multirow[t]{2}{*}{ Non-voluntary placement (LVU) } & $-0.143 * *$ & $-0.128 * *$ & $-0.125 * *$ & $-0.124 * *$ & $-0.130 * *$ & $-0.116^{*}$ & -0.132 \\
\hline & $(0.051)$ & $(0.041)$ & $(0.041)$ & $(0.043)$ & $(0.045)$ & $(0.046)$ & $(0.069)$ \\
\hline \multirow[t]{2}{*}{ Duration of treatment } & 0.127 & 0.653 & 0.083 & 0.158 & 0.285 & -0.128 & -1.400 \\
\hline & (1.599) & $(1.716)$ & $(1.767)$ & $(1.641)$ & $(1.530)$ & $(1.621)$ & $(2.409)$ \\
\hline \multirow[t]{2}{*}{ Treatment breakdown } & $-0.113 * *$ & $-0.111 * *$ & $-0.116 * *$ & -0.083 & -0.078 & -0.071 & -0.082 \\
\hline & $(0.048)$ & $(0.051)$ & $(0.054)$ & $(0.052)$ & $(0.050)$ & $(0.055)$ & $(0.106)$ \\
\hline \multirow[t]{2}{*}{ Treatment breakdown initiated by the social services } & $-0.059 * *$ & $-0.044^{*}$ & $-0.040^{*}$ & $-0.038 *$ & -0.038 & -0.038 & -0.051 \\
\hline & $(0.019)$ & $(0.019)$ & $(0.020)$ & $(0.019)$ & $(0.020)$ & $(0.022)$ & $(0.037)$ \\
\hline \multirow[t]{2}{*}{ Replacement after ended treatment } & $-0.109 * *$ & $-0.133 * *$ & $-0.171 * * *$ & $-0.141 * *$ & $-0.123 * *$ & $-0.168 * * *$ & -0.088 \\
\hline & $(0.055)$ & $(0.057)$ & $(0.056)$ & $(0.058)$ & $(0.057)$ & $(0.058)$ & $(0.111)$ \\
\hline
\end{tabular}

The table gives the estimated effect of planned duration of treatment on the dependent variables in the left column. All variables include a constant. Specification (2) includes control variables for teenagers characteristics; (3) teenager and municipality characteristics; (4) teenager and facility characteristics; (5) teenager, facility and treatment characteristics; (6) teenager, facility, treatment and municipality characteristics; (7) teenager and municipality characteristics and facility fixed effects. An indicator variable for non-voluntary placement is included in the vector of teenager characteristics except when it is the dependent variable. The precise content of each vector of control variables are given in Table A1. Standard errors are heteroskedasticity-robust and clustered at the facility level in all specifications except for (7). One star denotes statistical significance at the ten percent level; two stars at the five percent level, and three stars at the one percent level in a two-sided test. 
Table 3. Post-treatment outcomes

\begin{tabular}{|c|c|c|c|c|c|c|c|}
\hline Dependent variable & (1) & (2) & (3) & (4) & (5) & (6) & (7) \\
\hline \multirow[t]{2}{*}{ Conviction: Any crime } & $-0.113 * *$ & $-0.100^{*}$ & $-0.136^{* *}$ & $-0.136^{* *}$ & $-0.150 * *$ & $-0.194 * *$ & -0.116 \\
\hline & $(0.057)$ & $(0.059)$ & $(0.065)$ & $(0.066)$ & $(0.069)$ & $(0.075)$ & $(0.176)$ \\
\hline \multirow[t]{2}{*}{ Conviction: Violent crime } & $-0.100^{*}$ & $-0.096^{*}$ & $-0.105^{*}$ & $-0.117 * *$ & $-0.122 * *$ & $-0.131 * *$ & -0.117 \\
\hline & $(0.055)$ & $(0.051)$ & $(0.057)$ & $(0.052)$ & $(0.049)$ & $(0.058)$ & $(0.162)$ \\
\hline \multirow[t]{2}{*}{ Imprisoned } & -0.037 & -0.028 & -0.020 & -0.029 & -0.036 & -0.035 & -0.001 \\
\hline & $(0.048)$ & $(0.047)$ & $(0.056)$ & $(0.047)$ & $(0.048)$ & $(0.060)$ & $(0.125)$ \\
\hline \multirow[t]{2}{*}{ Mental health problems } & $-0.109 * *$ & $-0.121 * *$ & $-0.161 * * *$ & -0.095 & -0.079 & $-0.125^{* *}$ & -0.205 \\
\hline & $(0.051)$ & $(0.054)$ & $(0.050)$ & $(0.058)$ & $(0.055)$ & $(0.053)$ & $(0.136)$ \\
\hline \multirow{2}{*}{ Education above primary } & 0.064 & 0.081 & 0.072 & 0.088 & 0.104 & 0.073 & 0.035 \\
\hline & $(0.063)$ & $(0.069)$ & $(0.077)$ & $(0.075)$ & $(0.080)$ & $(0.088)$ & $(0.176)$ \\
\hline \multirow[t]{2}{*}{ Welfare recipient } & 0.040 & 0.045 & 0.036 & 0.023 & 0.033 & 0.017 & 0.070 \\
\hline & $(0.057)$ & $(0.059)$ & $(0.063)$ & $(0.064)$ & $(0.063)$ & $(0.068)$ & $(0.168)$ \\
\hline
\end{tabular}

The table gives the estimated effect of planned duration of treatment on the dependent variables in the left column. All variables include a constant. Specification (2) includes control variables for teenagers characteristics; (3) teenager and municipality characteristics; (4) teenager and facility characteristics; (5) teenager, facility and treatment characteristics; (6) teenager, facility, treatment and municipality characteristics; (7) teenager and municipality characteristics and facility fixed effects. An indicator variable for non-voluntary placement is included in the vector of teenager characteristics. The precise content of each vector of control variables are given in Table A1. Standard errors are heteroskedasticity-robust and clustered at the facility level in all specifications except for (7). One star denotes statistical significance at the ten percent level; two stars at the five percent level, and three stars at the one percent level in a two-sided test. 
Table 4. Outcomes by sex of teenager in care

\begin{tabular}{lcc}
\hline Dependent variable & Boys & Girls \\
\hline Treatment breakdown & $-0.151^{* *}$ & -0.069 \\
Treatment continued & $(0.071)$ & $(0.073)$ \\
& $-0.144^{*}$ & -0.116 \\
Conviction: any crime & $(0.076)$ & $(0.087)$ \\
& $-0.210^{* *}$ & -0.018 \\
Conviction: violent crime & $(0.088)$ & $(0.084)$ \\
& $-0.206^{* *}$ & -0.038 \\
Mental health problems & $(0.099)$ & $(0.049)$ \\
& $-0.210^{* * *}$ & -0.077 \\
& $(0.073)$ & $(0.088)$
\end{tabular}

The table gives the estimated effect of planned duration of treatment on the dependent variables in the left column. All variables include a constant and controls for teenagers characteristics other than sex. Standard errors are heteroskedasticity-robust and clustered at the facility level in all specifications. One star denotes statistical significance at the ten percent level, two stars at the five percent level and three stars in at the one percent level in a two-sided test. 